\title{
Patriotas sociales. \\ La izquierda ante el nacionalismo español*
}

\author{
Antonia María Ruiz Jiménez \\ Luis Navarro Ardoy \\ Elena Ferri Fuentevilla \\ Universidad Pablo de Olavide. Facultad de Ciencias Sociales. Departamento de Sociología \\ amruiz@upo.es; lnavard@upo.es; eferfue@upo.es
}

\section{Resumen}

Este artículo analiza el patriotismo español entre los partidos de izquierda de ámbito estatal y sus partidos federados o ideológicamente asimilables. Se basa en el análisis de treinta entrevistas a cuadros medios de esos partidos en las comunidades autónomas de Madrid, Cataluña, Andalucía y Galicia. Los resultados confirman que, a pesar de las conceptualizaciones estrechas que han dominado el debate sobre este tema, puede afirmarse la existencia de un patriotismo de la izquierda. Es decir, las élites de izquierda entrevistadas se sienten vinculadas con España; una actitud que expresa afecto, lealtad y preocupación fundamentalmente por el grupo (con una fuerte connotación de clase), antes que por el territorio. Posiblemente, la situación de crisis en que se recogen los testimonios (entrevistados en 2012) hace que los entrevistados sometan la definición de la comunidad política a preguntas y a críticas respecto a su sentido y a las prioridades que, aparentemente, no emergen en situaciones de normalidad, a tenor de lo reseñado en la literatura sobre el tema.

Palabras clave: nación; nacionalismo del bienestar; patriotismo de izquierda; patriotismo social; nación española; partidos de ámbito estatal; PSOE; IU

* Este artículo está asociado al proyecto "Nacionalismo español: discursos y praxis desde la izquierda, 1982-2008”, financiado por el Ministerio de Ciencia e Innovación (Ref. CSO2008-1182 CPOL) http://www.upo.es/proyectos/nacionalismo_esp/index.jsp/. 


\section{Abstract. Social Patriots: The Spanish Left Faced with Spanish Nationalism}

This article analyses Spanish patriotism among state-wide leftist parties in Spain and their federations or ideological equivalents. The investigation rests on the analysis of thirty semi-structured interviews with middle-ranking officials in Madrid, Catalonia, Andalusia and Galicia. The findings confirm that, despite the predominance of narrow understandings of the concept, the existence of Spanish patriotism among state-wide leftist parties can be affirmed. That is, those interviewed feel attached to Spain; an attitude expressed through beliefs that imply belonging, fondness, loyalty and concern mainly focused on the group (with a strong social class connotation) rather than the territory. The fact that the testimonies were recorded in 2012 during a deep economic crisis may have prompted the respondents to question and criticize the concept of political community (its meaning, priorities, etc.), which do not seem to occur in normal situations according to the literature.

Keywords: nation; welfare nationalism; left-wing patriotism; social patriotism; Spanish nation; state-wide parties; PSOE; IU

\section{Sumario}

1. Nación, patria e ideología

2. Diseño de la investigación: decisiones y justificaciones

3. Resultados de los análisis
4. Conclusiones

Referencias bibliográficas

Anexo 1

Anexo 2

\section{Nación, patria e ideología}

Este artículo analiza cómo los partidos de izquierda de ámbito estatal y sus partidos federados o ideológicamente asimilables («hermanos», en palabras de los propios entrevistados) ${ }^{1}$ conciben la nación y la identidad nacional españolas desde un plano afectivo. Como señalamos más adelante, el nacionalismo es una cuestión problemática para la izquierda, particularmente en España. No obstante, su estudio es relevante, porque el sentimiento de pertenencia a un grupo nacional (la identidad nacional) otorga estabilidad y continuidad a las estructuras políticas con las que se vincula (el Estado) (Easton, 1965; Linz, 1973; Smith, 1991; Dalton, 1998, 2004; Herderson y McEwen, 2005). La identidad nacional de la izquierda es, además, importante, porque esta opción

1. Como partidos de izquierda de ámbito nacional, nos referimos a IU y a PSOE. Véase, en el anexo 1, el desglose de los partidos incluidos en el análisis. En el apartado de metodología, se justifica su elección en 2012 (cuando realizamos el trabajo de campo), así como la asimilación entre estos partidos y los que están federados o asociados a ellos. Aunque formalmente algunos son independientes, comparten con las formaciones a las que se asimilan un pasado común, el ser no nacionalistas periféricos y su ubicación ideológica. En determinados casos, además, los propios entrevistados los definen como "partidos hermanos». 
ideológica es la elegida por más de un tercio del conjunto de la ciudadanía española ${ }^{2}$.

Como se expone en la revisión de la literatura en esta primera parte del artículo, el objeto de análisis es interesante, por la difícil y contradictoria relación que ha existido entre los partidos de izquierda y el nacionalismo ${ }^{3}$. En el segundo apartado, se justifica el diseño de la investigación y la metodología utilizada. El análisis de la información, en el apartado de resultados, desarrolla la caracterización de España entre la izquierda como comunidad de pertenencia y los valores que se asocian con esta idea. En las conclusiones, se resumen los hallazgos principales y sus implicaciones en la actualidad.

Ciertamente, la relación entre partidos de izquierda y nacionalismo ha sido históricamente difícil y contradictoria, tanto por razones estructurales como coyunturales. Entre las primeras, debido a la oposición que existe en sus fundamentos ideológicos (Howell, 1986; Laxer, 2001; Schwarzmantel, 2012; Kasprzak, 2012). En tanto que las ideologías de izquierda son universalistas (Hobsbawm, 1996; Kasprzak, 2012: 587), el nacionalismo se fundamenta en la distinción y en los derechos únicamente de un grupo particular de personas, del que se excluye al resto ${ }^{4}$ (Howell, 1986: 4; Yack, 2001: 530; Goodhard, 2006: 13-15). Así, cuando la izquierda aborda la cuestión de la ciudadanía nacional, lo hace a la defensiva y con estrategias inciertas (Goodhard, 2006: 9), presentando problemas incluso para nombrar el país al que debe representar en su conjunto (Hobsbawm, 1996: 45-6; Laxer, 2001).

Desde un punto de vista coyuntural, esta incomodidad tiene mucho que ver con la relación que las ideologías de derecha establecieron con el nacionalismo. Antes de 1848, los conservadores eran antinacionalistas como una estrategia para conservar sus privilegios de clase frente a los principios del nacionalismo cívico inspirado por las revoluciones francesa y americana. A medida que estas fuerzas avanzaban y se demostraban imparables, la derecha se fue alineando con un tipo diferente de nacionalismo étnico-cultural, desafiando las variedades de nacionalismo cívico y radical asociadas con la izquierda (Laxer, 2001: 14-15; Erk, 2010: 425-6). El éxito de la derecha para ocupar el concepto de nacionalismo y, en última instancia, su alianza con el fascismo y el racismo nacionalista es lo que mantiene actualmente a muchas personas de

2. En las elecciones generales de noviembre de 2011, el PSOE obtuvo el $28,8 \%$ de los votos y fue el segundo partido más votado, e IU, el $7 \%$ (tercer partido más votado).

3. Los conceptos de patriotismo y nacionalismo se utilizan indistintamente para designar la concepción de una persona sobre su pertenencia y su cercanía a la comunidad política de referencia. El interés del artículo no reside en valorar el amplio debate sobre el significado y la pertinencia de uso de ambos conceptos (véase, entre otros, Connor, 1994, y Billig, 1995). Por el contrario, partimos de la afirmación de Ward (1998: 2) de que el patriotismo no se puede separar de la cuestión de la identidad nacional, ya que incluso en su acepción más simple, «el amor al país», el objeto debe ser definido para poder ser amado. La nación debe ser «imaginada» de algún modo que sea merecedora de afecto.

4. Otra razón por la que la izquierda rechaza el nacionalismo es por su caracterización como una ideología burguesa y capitalista, cuya intención es diluir la conciencia de clase social (Howell, 1986; Kasprzak, 2012; Schwarzmantel, 2012). 
izquierda alejadas y recelosas de las ideologías nacionalistas en general y del nacionalismo español en particular.

No obstante, las ideologías de izquierda no han sido ajenas a las políticas de identidad, y han tratado, con diferentes estrategias y grados de éxito, definirse igualmente como patrióticas frente a las ideologías conservadoras. Primero, de forma paralela al proceso de descolonización que ofrecía la oportunidad de atacar al "nacionalismo opresor», representado por los imperios, con el «nacionalismo liberador», simbolizado por las naciones oprimidas (Goodhart, 2006: 19; Erk, 2010: 426; Kasprzak, 2012: 596). Más tarde, mediante la representación y la defensa, por parte de la llamada nueva izquierda, de identidades minoritarias o marginalizadas (Hobsbawm, 1996; Talshir, 2005: 321; Farneti, 2012). Recientemente, la izquierda ha trabajado en el acomodo de distintas identidades étnicas, culturales o nacionales en un mismo Estado, apelando al concepto de multiculturalismo. Estas elaboraciones han recibido denominaciones diversas, como nacionalismo constitucional (Bastida, 1998, 2007), nacionalismo pluralista (Máiz, 2003), patriotismo constitucional (Habermas, 1992; Laborda, 2002; Müller, 2007) y patriotismo democrático (Muñoz, 2012). Además, cabe mencionar los conceptos de patriotismo social (Field, 1992) y de nación de clase (Lepsius, 2004), centrados en la idea de que los intereses de la nación coinciden con los intereses de las clases trabajadoras (es decir, no pueden plantearse como patrióticos planes que vayan en contra de la igualdad o la justicia social). La evolución de estos planteamientos dentro de la izquierda ha sido poco trabajada desde la sociología o la ciencia políticas, aunque existen ejemplos puntuales de su reaparición (Jackson, 2012). Con algo más de detalle, se ha estudiado la idea de nacionalismo del bienestar (McEwen, 2002; McEwen y Moreno, 2005), que podríamos situar cerca de la idea de patriotismo social, por sus componentes de redistribución, justicia e igualdad social.

En resumen, no se trata de que nacionalismo e ideología de izquierda no puedan combinarse, o no lo hayan hecho en el pasado de forma exitosa. De forma general, lo que refleja esta literatura es que, a diferencia de la derecha, la izquierda no ha sido capaz de encontrar la fórmula definitiva para hacerlo5.

Estas tendencias se han concretado de un modo particular en la España democrática actual. Diferentes autores han apuntado hacia la autocontención nacionalista de la izquierda: una resistencia a hablar sobre España que habría dejado la definición de la nación española en manos de la derecha, quien habría dado pasos más claros y decididos hacia su definición (Bastida, 2002;

5. Esta situación se ilustra, por ejemplo, en el caso de España, donde es evidente que la izquierda de ámbito no estatal en Cataluña y el País Vasco ha sido capaz de incorporar exitosamente los argumentos nacionalistas con una ideología de izquierda (Dinas, 2012), en tanto que los partidos de ámbito estatal parecen tener más dificultades, al menos o como mínimo, para hacer ese discurso explícito al mismo nivel que la izquierda nacionalista. En cualquier caso, son las dificultades de la izquierda de ámbito estatal el objeto de interés de este artículo. 
De Blas, 2003: 772; Mateo, 2005; Muñoz, 2012: 62) ${ }^{6}$. Pero, ¿significa esto que la izquierda no se siente vinculada con España, que se siente ajena a los españoles? ¿Que, efectivamente, existe una apatía patriótica entre las élites de izquierda (Molina, 2009: 48)? Son estas las preguntas fundamentales a las que se pretende responder en este artículo.

Según la literatura centrada en España, si bien tanto la derecha como la izquierda rechazaron inicialmente hablar de la nación española abiertamente, como reacción a la monopolización del patriotismo español por parte del régimen franquista (Núñez, 2010), esta situación parece haberse prolongado entre la izquierda, en gran parte por su alianza estratégica con los nacionalismos periféricos (De Blas, 1991; Mar-Molinero y Smith,1996; Núñez, 2010; Quiroga, 2008, 2011)7. No obstante, creemos que estas conclusiones serían diferentes de considerar una definición más amplia de nacionalismo. En concreto, proponemos usar la definición de Bar-Tal (1997) de patriotismo como una actitud de pertenencia, asociada con emociones y sentimientos positivos, que se expresa a través de creencias que connotan pertenencia, afecto, lealtad, orgullo y preocupación por el grupo y el territorio. Este patriotismo, en un sentido similar a la dimensión afectiva de la comunidad política expresada por Easton (1965), es independiente del tipo de estructura político-administrativa del Estado, puede existir previamente a su creación o puede desarrollarse a posteriori (Martínez-Herrera, 2002). En cualquier caso, la existencia de dicho sentimiento da estabilidad a las estructuras político-administrativas (al Estado), sirve para legitimarlas y es, por lo tanto, cultivado habitualmente desde dichas instancias (Alvarez, 2001: 15; Martínez-Herrera, 2002: 425-6).

Entendido así, nuestra pregunta de investigación puede reformularse en los siguientes términos: ¿Hasta qué punto se pueden encontrar creencias que connoten afecto, lealtad, orgullo y preocupación hacia el conjunto de los españoles, y hacia España, entre las élites de izquierda entrevistadas? ¿En qué se basan o cómo se justifican esas creencias?

La bibliografía general sobre PSOE e IU no ayuda a responder a dichas preguntas, y es especialmente escasa en el caso de $\mathrm{IU}^{8}$. En general, predominan las revisiones históricas, con alusión a los fracasos y a los éxitos electorales de los partidos y las trayectorias políticas de sus dirigentes, sus estructuras organizativas y sus facciones territoriales. Respecto a la idea de España, se recogen

6. Ya que además, la polarización de este eje de competición nacionalista beneficia electoralmente tanto al partido conservador como a los nacionalistas periféricos (Amat, 2012).

7. Estas afirmaciones se refieren al periodo contemporáneo. Existe, no obstante, una evidencia que pone de manifiesto que los conceptos de izquierda y nacionalismo se han combinado de diferentes maneras y en diferentes momentos en nuestro país - de forma general, o en los escritos de algunos teóricos de la izquierda en particular (véanse, entre otros, los trabajos de contemporáneos de Daniel Guerra Sesga, Jorge del Palacio, Luis Ramiro, Ferran Archilés o Vega Rodríguez-Flores Parra)—. A pesar de ello, y como hemos expuesto, la literatura consultada coincide en señalar que la izquierda de ámbito estatal no ha sido capaz de recuperar estas tradiciones después de la Transición.

8. Pueden consultarse, no obstante, autores como Luis Ramiro, Ferran Archilés o Vega Rodríguez-Flores. 
casi en exclusiva referencias al modelo de organización territorial. Son comunes igualmente las biografías y las autobiografías de líderes políticos de izquierda (Márquez, 1983; Maravall, 2003, 2008; Guerra, 2013; Anguita y Monedero, 2013a, 2013b; Garzón, 2013, 2014).

De forma más detallada, antes de los años ochenta, existen, sobre todo, estudios de determinados momentos de la historia del socialismo, especialmente la Segunda República, aproximaciones a sus figuras relevantes, y numerosas hagiografías de antiguos militantes. Suelen ser trabajos poco rigurosos, al carecer de un estudio sistemático de la bibliografía sobre la materia y, especialmente, por la ausencia de información sobre sus fuentes primarias (Molina, 2014: 163). Durante los gobiernos de Felipe González, existen libros más completos de la historia del socialismo español, con gran atención a la Guerra Civil, al exilio, a la dictadura de Franco y a la Transición (Tezanos, 1983; García, 1985; Gillespie, 1989; Martín, 1989; Mateos, 1993; Juliá, 1997). También se publican trabajos novedosos sobre los nacionalismos en España con algunas referencias a los partidos de izquierda (Linz, 1993; Fox, 1997). Sin embargo, no encontramos estudios que profundicen en los sentimientos hacia España o hacia los españoles entre los partidos de izquierda, en su patriotismo, más allá de su forma de organización territorial.

La primera década del siglo XXI representa un momento de inflexión. Estos años (y los siguientes) arrojan mayor interés y reflexión académica, y las publicaciones sobre partidos de izquierda crecen de manera gradual. Aunque el foco de atención sigue muy centrado en la estructura organizativa (Méndez, 2000), la evolución ideológica y las estrategias de competición electoral (Verge, 2007), empiezan a utilizarse referencias a la concepción de España en su dimensión afectiva y también a la variable subjetiva de identificación nacional para el estudio de diferentes tendencias políticas (Balfour y Quiroga, 2007; Jiménez y Navarro, 2015). Recientemente, cabe mencionar algunos trabajos que señalan el desarrollo de un patriotismo constitucional en España, dentro de la izquierda española desde los años 1990, y apropiado por la derecha posteriormente, a partir del 2000 (Núñez, 2010; Ballester, 2011).

En suma, excepto contadas referencias generales centradas en líderes destacados, sabemos poco del patriotismo español de la izquierda de ámbito estatal. Como hemos mencionado, en primer lugar, porque los trabajos específicos sobre estos partidos y su concepto de nación española han sido relativamente escasos hasta fechas recientes; en segundo lugar, porque los que existen, la mayor parte de carácter historiográfico, suelen alcanzar hasta la década de 1990, con algunas excepciones.

Frente a estos hallazgos previos, nuestra hipótesis es que una versión más amplia del concepto de patriotismo, basada en la definición de Bar-Tal (1997), permitirá medir mejor el apego de la izquierda a la nación española. Más allá de esta hipótesis general, nuestra investigación es exploratoria respecto al sentido y al contenido de este posible patriotismo de la izquierda en España. El valor añadido del texto que presentamos, frente a los trabajos existentes, se centra en cuatro aspectos: 
1. Transparencia y rigor en cuanto al proceso de producción y análisis de los datos.

2. Un diseño comparativo que incluye las variables de ideología y territorio.

3. Un enfoque centrado en los cuadros medios de los partidos (élites locales y regionales), que raramente han sido objeto de análisis.

4. Un análisis que va más allá de la mera preferencia e interpretación de la organización territorial del Estado, para interesarse por la dimensión afectiva o patriótica hacia España y los valores que se le asocian desde la izquierda.

\section{Diseño de la investigación: decisiones y justificaciones}

La evidencia que utilizamos para analizar el patriotismo español entre la izquierda se basa en el análisis de treinta entrevistas abiertas semiestructuradas con cuadros medios de partidos de izquierda de ámbito estatal y sus partidos federados o "hermanos", que hemos asimilado a efectos de presentación de los resultados obtenidos en Cataluña, Galicia, Madrid y Andalucía (véase el anexo 1) $)^{9}$. Esta lista de partidos excluye a Podemos, debido al momento en que se diseña el proyecto de investigación, dentro del cual se inserta este artículo (2008), y en que se recogen los datos de los entrevistados (2012). No obstante, como señalaremos en las conclusiones, existen paralelismos entre nuestros hallazgos y los discursos de Podemos, que apuntamos y que serán objeto de investigaciones posteriores.

Las comunidades se eligieron en base a criterios analíticos por los perfiles identitarios de su opinión pública, comunes para los grupos de discusión que también se realizaron con simpatizantes de estos partidos en el marco del mencionado proyecto Nacionalismo español: discursos y praxis desde la izquierda ${ }^{10}$.

9. A efectos prácticos, para presentar y resumir la información, hemos agrupado a todos los entrevistados en dos dimensiones de análisis: los que hemos asimilado a la esfera ideológica de IU y los que hemos asimilado a la esfera ideológica del PSOE. Existe un continuo entre el partido único y partidos completamente separados (Smiley, 1987; Thorlakson, 2001) a lo largo del cual se han movido históricamente los partidos que hemos incluido en el análisis. Aunque actualmente algunos autores señalan que es más conveniente hablar de partidos diferentes — particularmente para IU-ICV y PSC-PSOE entre nuestros casos (Verge y Barberá, 2009)—, debido a las distancias en la política organizativa, la definición ideológica y programática, así como en la política de alianzas, hemos ponderado tanto la existencia de un pasado común federado como la cercanía ideológica en el presente para decidir sobre esta agrupación en relación con la presentación de los resultados. El hecho de que los partidos que hemos asimilado tengan independencia para plantear su definición ideológica y programática no implica necesariamente su distanciamiento ideológico. De hecho, nuestra decisión es respaldada por la cercanía con la que los encuestados ubican a los partidos políticos ideológicamente: PSOE: 4,10; PSC: 4,52; PSdeG: 3,97 / IU: 2,29; ICV-EUiA: 2,83 (escala de 0 a 10, siendo 0 extrema izquierda y 10, extrema derecha) (estudio número 2956del CIS, de 2012). Además, como hemos apuntado, algunos de nuestros entrevistados utilizan explícitamente el término partidos hermanos, tanto los asimilados a IU como al PSOE (en total, cuatro entrevistados - 3 asociados al PSOE y 1 a IU— utilizan esta expresión de forma literal).

10. Véase la nota 1. 
La elección de un perfil político con cargos intermedios ha sido intencionada, tanto para maximizar el número de entrevistas como porque, suponíamos, tendrían un discurso más relajado y menos sujeto a las claves electoralistas y a la formulación oficial del partido. Ello debía permitirnos profundizar en un tema que, como se ha dicho, ha tendido a evitarse desde la izquierda ${ }^{11}$. La opinión de estos puede ser conocida con mayor facilidad a través del eco que reciben en los medios de comunicación, a los que tienen mejor y mayor acceso que las élites más alejadas de los principales focos mediáticos, y sobre los que pueden ejercer determinado control (Riker, 1986; Banducci et al., 2004; Entman, 2007). Así, ha sido posible, por ejemplo, encontrar discursos de líderes de Podemos que nos permiten valorar hasta qué punto comparten ideas y argumentos con nuestros entrevistados. En cambio, los cuadros intermedios apenas han sido objeto de análisis, ya sea en relación con este o con otros temas ${ }^{12}$.

Las entrevistas se realizaron durante el año 2012. El momento de recoger las opiniones de los entrevistados, y por tanto el contexto respecto al cual han de interpretarse las respuestas, no puede desligarse de la situación de crisis económica que España atravesaba en aquellos momentos. Sin embargo, no consideramos dicha situación como un impedimento para llevar a cabo el análisis propuesto. Creemos que precisamente este escenario somete la definición de la comunidad política a una serie de tensiones respecto a su sentido, a sus prioridades, etc., lo que permite aflorar un discurso mucho más explícito de lo que es habitual entre la izquierda, a tenor de los hallazgos previos en la literatura.

En este sentido, la crisis, como concluye gran número de investigaciones, ha tenido efectos más allá de lo puramente económico, en lo social, en los derechos y en las obligaciones de los ciudadanos, así como en el tipo de pacto social por el que se rige actualmente nuestro país (véase, entre otros, Fundación Alternativas, 2013; Fundación Foessa, 2013; Pérez y Navarro, 2013). Esta situación afecta tanto a la dimensión político-administrativa de la comunidad política como a la dimensión afectiva o imaginada, es decir, al sentimiento de pertenencia (Easton, 1965; Anderson, 1991). Respecto a la primera, la forma actual de organización territorial está sometida a tensiones tanto recentralizadoras como descentralizadoras e independentistas: basta consultar la prensa para comprender que desde ambas posturas se utilizan argumentos ligados a la crisis

11. De hecho, como citamos más adelante, los resultados de este artículo no coinciden exactamente con los que se extraen de las posiciones oficiales del partido a través del análisis de sus programas electorales (Ferri y Ruiz, 2015), lo que pensamos que responde, en parte, a esta estrategia. Los entrevistados son más proclives a demostrar apego a la nación española, en tanto que en los programas se discute, sobre todo, la dimensión político-administrativa del Estado.

12. Pueden citarse, como excepciones, algunos estudios centrados en el discurso parlamentario, como Grad y Martín, 2003; Coller y Santana, 2009; Coller y Carrillo, 2014. En nuestro caso, además de parlamentarios, entrevistamos a concejales, portavoces del partido y representantes de juntas de distrito. 
económica como justificación en un sentido y en el contrario. En la segunda de las dimensiones (la afectiva), especialmente el alcance de la solidaridad, que ha sido uno de los pilares en la construcción del modelo de sociedad española desde la Transición, y que es una de las manifestaciones más claras de la existencia de una comunidad política (Martínez-Herrera, 2002: 84; McEwen, 2002; McEwen y Moreno, 2005; Kaina y Karolewski, 2009: 14), está siendo transformado. Estos intentos y transformaciones repercuten de manera directa en la dimensión afectiva, porque los sentimientos hacia la comunidad política afloran explícitamente. Por ello, entendemos que es más probable que se origine un discurso más amplio y profundo sobre un tema que no ha sido central entre la izquierda española, al menos de una forma explícita ${ }^{13}$. En cualquier caso, defendemos que la obtención de nuestros datos coincidiendo con la crisis económica no invalida nuestros hallazgos sobre el patriotismo de la izquierda en España.

En cuanto a la técnica de investigación, optamos por entrevistas abiertas semiestructuradas, con el propósito de alcanzar un análisis más fino y profundo del patriotismo español que el obtenido a partir de fuentes oficiales a través del análisis de programas electorales entre 1977 y 2015 (Ferri y Ruiz, 2015). Las entrevistas son una herramienta adecuada para el análisis del discurso implícito de los entrevistados sobre la idea de España, así como para profundizar en sus razones, argumentos, justificaciones y significados (Ruiz, 2009). Con este tipo de entrevista, implementamos un análisis sistemático pero no rígido (Coffey y Atkinson, 2003: 12) entre diferentes perfiles políticos de entrevistados y por comunidades autónomas. A las transcripciones completas de las entrevistas, se ha aplicado un esquema de codificación elaborado de forma iterativa por dos de los investigadores que firman este artículo. Se ha optado por una codificación que distingue entre valores, por un lado, y actitudes y creencias, por otro (Saldaña, 2013: 110-115) ${ }^{14}$. Tanto la codificación como la recuperación selectiva de la información a posteriori siguen el método NCT (Noticing, Collecting and Thinking) sugerido por Friese (2012), mediante la asistencia del programa ATLAS.ti, así como algunas de las técnicas de resumen, descubrimiento y comparación ilustradas por Miles et al. (2014).

13. Obviamente, la crisis económica no es el único factor que puede haber provocado la reactivación del debate nacional en el Estado español. El agotamiento del modelo del Estado autonómico y la sentencia del Tribunal Constitucional del 28 de junio de 2010, al anular partes del Estatuto de Cataluña, han desempeñado igualmente un papel importante. Particularmente, el uso que el PP hace del patriotismo constitucional merece señalarse: Kymlicka (1996: 122-125) sugiere que la utilización del concepto estricto de ciudadanía anclado en la Constitución del país como un elemento común de identidad compartida que trata de imponerse sobre todos los individuos, ignorando las demandas de las minorías nacionales, sin referencia a la pertenencia al grupo, simplemente agrava la alienación de las minorías nacionales e incrementa el deseo de secesión.

14. El siguiente enlace recoge el esquema final de codificación como indicador de fiabilidad (reproducibilidad) de nuestros análisis: http://www.upo.es/proyectos/export/sites/proyectos/ nacionalismo_esp/carpetadescar/Esquema_de_codificacixn_final_aplicado_a_las_entrevistas_con_cuadros_medios_del_PSOE_e_IU.pdf 


\section{Resultados de los análisis}

\section{1. "¿España? ;Qué pregunta más graciosa!"}

El título de esta sección ilustra a la perfección el sentimiento de sorpresa y desconcierto que genera entre las élites de izquierda una pregunta genérica sobre qué es España. Las respuestas que se obtienen deben ser analizadas en un doble nivel: uno más explícito e inmediato (en el que España incluso se niega) y otro más profundo, implícito y menos estudiado (en el que el concepto de España se elabora con un significado acorde a los valores, las actitudes y las creencias del entrevistado):

¡Puf...! ¡Qué pregunta más graciosa! A mí, España no me gusta, o sea, a mí me gusta la gente de España, me gustan los gallegos, me gustan los catalanes, me gustan los vascos, me gustan hasta los castellanos a pesar de muchas leyendas y de la propia historia de España. Pero el Estado español no me gusta. (Entrevista 25)

En el primero de los niveles, encontramos discursos y lugares comunes que han sido ilustrados en otros trabajos (Ruiz y González, 2007). De forma muy sintética, señalamos la reacción con silencios, dudas, vacilaciones, expresiones de sorpresa o definiciones incompletas y/o contradictorias. Hasta dos de cada tres entrevistados muestran alguna dificultad para definir a España o no se encuentran cómodos hablando del tema. Este resultado es mucho más frecuente entre los catalanes, donde todos, salvo uno,manifiestan algún problema o experimentan incomodidad ante nuestra petición. Por el contrario, a los gallegos y a los madrileños les resulta más fácil hablar de España en comparación con las otras comunidades. Si atendemos a la ideología, estas dicultades son más habituales entre élites del grupo asimilado a IU (donde tres de cada cuatro las manifiesta) que del grupo asimilado al PSOE, donde lo hace algo más de la mitad.

Los entrevistados son conscientes de estas dificultades y entienden (excepto los catalanes) que son ampliamente compartidas por la ciudadanía simpatizante de sus partidos, que se encontraría, así, alienada de su identidad nacional española. Esta percepción aparecede manera notable en el discurso de madrileños y, en menor medida, de gallegos y andaluces. Los catalanes, a pesar de sentirse personalmente incómodos en referencia a la temática, no desarrollan esta idea de alienación de las bases con una identidad nacional española.

Cuando las dificultades se explicitan, se relacionan con el rechazo a un modelo concreto de nación española, que identifican como propio de la derecha (menos, o poco, respetuoso con la pluralidad de España), y que los entrevistados parecen haber asimilado como el único significado posible del concepto, al menos en este nivel más evidente y explícito del discurso. Concepto que, como hemos señalado, resulta negado. Al igual que ocurre entre simpatizantes de partidos de izquierda, el rechazo y la dificultad se hace más palpable y evidente en relación con los símbolos de la patria (Ruiz et al., 2015), también por 
estar identificados como continuación del régimen franquista anterior o como secuestrados por la derecha española contemporánea.

Yo no creo que el país [...] haya cambiado de posición. Franco hizo muchísimo daño también en este campo, claro, él se... se autoidentificó con la nación española. Claro, eso hace daño, es evidente, hizo mucho daño. (Entrevista 22)

Las referencias a los símbolos entre las élites entrevistadas son mayoritarias y presentan, a su vez, la mayor frecuencia de aparición del conjunto de códigos analizados. Todos los entrevistados en Andalucía (siete), Galicia (cinco) y Madrid (nueve) incluyen en su discurso alguna cuestión referida a los símbolos, en tanto que en Cataluña es una idea menos frecuente (lo hacen seis de sus nueve entrevistados). Tanto en el PSOE como en IU y los partidos asimilados, prevalecen las referencias a los símbolos cuando se les pregunta directamente sobre España o surge el tema de manera espontánea. Especialmente, los entrevistados hablan de la bandera y del himno, aunque también de otros como la Constitución. Casi siempre se refieren a ellos con una connotación más negativa que positiva: como símbolos que no representan a la totalidad, que no son compartidos, que excluyen o dividen en algún caso y/o como símbolos de los que se ha apropiado la derecha.

No obstante, algunos entrevistados apuntan a cierto proceso de normalización de la cuestión nacional que se ha visto fortalecida con las victorias de equipos españoles en eventos deportivos internacionales, si bien no existe ninguna valoración unánimemente positiva sobre este hecho. Algunos apuntan a los esfuerzos de normalización del uso del término España por parte del gobierno de Zapatero. Y otros, finalmente, lo atribuyen al paso de las generaciones ${ }^{15}$.

Yo creo que hay mucha gente que, si no fuera por la selección española de fútbol, pues, seguiría avergonzándose de la bandera española. No le gusta a la gente salvo esto que te digo, que yo creo que la selección de fútbol ha hecho más por España que el monarca, por poner un ejemplo. (Entrevista 25)

Las generaciones futuras tendrán menos problemas con la bandera, porque, además, se olvidarán de lo que a nosotros nos cuesta más trabajo olvidar; y eso que yo tenía once años cuando murió Franco, pero cuesta mucho trabajo olvidar que eran la misma bandera y el mismo himno del dictador. (Entrevista 14)

Las dificultades para definir a España, o la incomodidad que produce entablar una conversación sobre este tema, representan solo una resistencia inicial a hablar de él. Salvo uno, todos los entrevistados terminan dando una o varias respuestas sobre el significado de España que han sido susceptibles de codificación. En esas respuestas, es destacable que sea definida primero como una

15. Esta creencia, sin embargo, es desmentida en el mencionado estudio de Ruiz et al. (2015), en el que se muestra que los jóvenes de izquierda continúan manteniendo una relación complicada con los símbolos debido, en parte, a la socialización familiar. 
comunidad de sentimiento (por la práctica totalidad de los entrevistados), más que como una mera estructura política y/o administrativa (siete de cada diez), aunque es frecuente que ambos tipos de concepciones de España se mezclen en el discurso (casi la mitad de los entrevistados aplica ambos tipos de definiciones) ${ }^{16}$. La literatura ha dejado estas otras definiciones más afectivas de la comunidad política española en un segundo plano, y se ha centrado en las cuestiones relacionadas con la organización territorial del Estado (dimensión político-administrativa). En los dos siguientes apartados, desarrollamos esta caracterización de España más allá de su estructura político-administrativa, como una comunidad de pertenencia y los valores que la izquierda asocia con esta idea ${ }^{17}$.

\subsection{España: más que un Estado multinivel}

Siguiendo a Easton (1965), distinguimos dos dimensiones en la definición de una comunidad política. Una, la que se refiere a la estructura política (un nivel político-administrativo, que es objetivo), por la cual todos los miembros de esa comunidad están sometidos a unas reglas comunes, y la que se refiere al sentimiento de pertenencia al (o a la vinculación afectiva con el) grupo (un nivel sentimental, que es subjetivo) (Easton, 1965). Para el caso de España, su existencia como estructura política, que definiríamos como Estado mutinivel (Martínez-Herrera, 2002, 2005), está fuera de toda duda. Sin embargo, su existencia como comunidad afectiva es discutida, ya que no todos los españoles se sienten cercanos a ella ${ }^{18}$. Para nuestros entrevistados, la concepción de España como comunidad política en un nivel afectivo implicaría descubrir en sus discursos que admiten formar parte del conjunto de los españoles y que comparten con ellos factores diferentes a los puramente político-administrativos. En relación con nuestra hipótesis sobre la existencia de un patriotismo de

16. Este resultado, curiosamente, no coincide con los hallazgos a partir del análisis de programas electorales (Ferri y Ruiz, 2015). Dadas las dificultades de la ideología de izquierda para incorporar el nacionalismo, cabría esperar un mayor énfasis en la dimensión políticoadministrativa que en la afectiva. Los programas electorales confirman esta respuesta, que no se habría modificado de forma notable durante el periodo democrático, tanto para la derecha como para la izquierda. Este posicionamiento más formal de los partidos contrastaría, no obstante, con los «anhelos patrióticos» de sus simpatizantes (Ruiz et al., 2015) y las visiones de sus élites intermedias, según apuntan los hallazgos en el presente artículo. Es decir, denota una cierta rigidez de las estructuras para reflejar un nacionalismo que es más evidente en los niveles intermedios y entre los simpatizantes de izquierda. Ambos elementos nos ayudan a entender el éxito de Podemos, frente al distanciamiento de los partidos tradicionales con la ciudadanía y su pérdida de votos.

17. En otro lugar, no obstante, hemos publicado el análisis de la dimensión político-administrativa para las mismas élites (Navarro et al., 2017).

18. El 16,3\% de la población española se siente más o únicamente de su comunidad autónoma que español; el 21,3\%, más o únicamente español que de su comunidad autónoma, y una mayoría, el $57,3 \%$, se siente tanto español como de su comunidad autónoma (estudio número 3126 del CIS (pregunta 40), Postelectoral elecciones generales 2015; véase, al respecto, Jiménez y Navarro, 2015). 
izquierdas, este sentimiento implicaría, además, la preocupación por el devenir de dicho grupo de pertenencia.

Una de las ideas recurrentes es la referencia a la existencia de una historia compartida, algo que también ha sido enfatizado por autores como Gellner (1998, 2008), Østerud (1999) y Smith $(2007,2010)$. La mitad de nuestros entrevistados considera que España se ha configurado tal y como es en la actualidad a través de su historia, no necesariamente con una visión idílica o grandiosa del pasado, sino también con una visión más negativa que apunta a la existencia de conflictos y enfrentamientos, de forma general, y a la Guerra Civil y la dictadura, de forma particular. La idea de historia compartida, que puede complacer más o menos a los entrevistados, se identifica como un elemento que perdura, que está presente y que determina el tipo de realidad que es España actualmente.

Al margen de una historia compartida, existen fórmulas muy diversas con las que los entrevistados definen a España más allá de sus características político-administrativas. Hasta tres de cada cuatro utilizan alguna expresión que incluye elementos, tanto de tipo étnico-cultural como de tipo cívico (Máiz, 2003). Entre ellas, pueden mencionarse la referencia a la existencia de lazos familiares, culturales o inclusive de sangre entre los ciudadanos que habitan los diferentes territorios que componen España; el reconocimiento de elementos comunes diversos frente al exterior; el orgullo por los logros culturales y/o políticos del país; la conceptualización de España como una realidad, como un espacio compartido, un espacio vital, una unidad y/o un acuerdo de convivencia, una construcción colectiva o un proyecto de futuro. Finalmente, la definición de España como una nación, una sociedad, o como «su gente» ${ }^{19}$.

Mi familia es inmigrante, mi madre es cordobesa, mi padre de Almería, con lo cual mi identidad cultural tiene mucho que ver con España. [...] Yo, a Cervantes, pues lo siento mío y a Machado, por tanto, yo me siento... En ese sentido, hay una identidad cultural con España. (Entrevista 1)

Obviamente, la gente tiene que estar orgullosa de sus buenas tradiciones, de su tierra, de sus buenas costumbres, de su idioma, de su cultura. Por supuesto, eso nunca tiene que desaparecer, faltaría más, ni en ninguna universalización ni nada. (Entrevista 18)

Estas definiciones de España como comunidad de pertenencia son menos frecuentes entre los catalanes, puesto que solamente hablan de ello dos de cada tres de los entrevistados allí. Tanto los madrileños como los andaluces se refieren con una asiduidad mayor que el resto a los sentimientos de orgullo y son, al mismo tiempo, los que más utilizan las expresiones de nación y sociedad aplicadas a España.

19. Incluso en el lenguaje con ciertos rasgos «populistas» pueden encontrarse paralelismos con Podemos. No obstante, las élites de los partidos tradicionales optaron por no desarrollarse en ese sentido. 
En suma, independientemente del rechazo inicial que produce la pregunta sobre qué es España, así como el uso del propio término España, los entrevistados manifiestan una creencia compartida sobre la existencia de una comunidad política de ámbito estatal en torno a la cual existen sentimientos de pertenencia, afecto, lealtad, orgullo y preocupación, quizás más orientados hacia el grupo que hacia el territorio. En resumen, encontramos indicios que denotan cierto patriotismo español entre la izquierda de ámbito estatal analizada. A continuación, exploramos qué valores aparecen asociados a esta definición de España como comunidad de pertenencia.

\subsection{Los valores patrióticos de la izquierda}

La aplicación de un esquema de codificación basada en valores (Saldaña, 2013: 111) nos ha permitido analizar de manera inductiva los principios ideológicos o morales por los que se guían los cuadros medios entrevistados cuando hablan de España. Frente a otras aproximaciones más usuales, pensamos que esta manera de proceder representa uno de los aportes más relevantes de la investigación. El analizar inductivamente el concepto de patriotismo de la izquierda nos permitirá, además, contrastar nuestra hipótesis.

Cuando las élites de izquierda hablan de España, el valor que aparece de forma más destacada es el de "nación social» (en tres de cada cuatro entrevistados) (véase Figura 1). Se trata de un discurso que enfatiza la igualdad entre los ciudadanos de todo el país independientemente de su comunidad de residencia, especialmente en lo que a los servicios públicos se refiere. Incluye también referencias a la solidaridad que los ciudadanos y las regiones más ricas deben tener con los ciudadanos y las regiones más pobres o menos favorecidas, así como la necesidad de proteger a las clases más bajas, las clases trabajadoras y los más débiles (por igual en todos los territorios). Las siguientes frases ilustran dicho valor, que encaja perfectamente con los conceptos de nacionalismo del bienestar y patriotismo social que mencionábamos al inicio del presente trabajo y que sigue teniendo resonancias de lucha de $\operatorname{clases}^{20}$.

Pero, en cambio, hay otras muchas cosas con las cuales podemos estar de acuerdo: que queremos un Estado social y que vamos a caracterizar el Estado social con un Estado de bienestar fuerte, con unos derechos sociales fuertes. (Entrevista 2)

20. Como apuntábamos en el apartado de metodología, aunque no tenemos entrevistas con líderes de Podemos, algunos de los discursos que es posible encontrar en la prensa repiten de forma casi idéntica algunos de los argumentos de nuestros entrevistados:

Y hoy decimos patria con orgullo y decimos que la patria no es un pin en la solapa, no es una pulsera. La patria es esa comunidad que asegura que se protege a todos los ciudadanos, que respeta la diversidad nacional, que asegura que todos los niños, sea cual sea el color de su piel, van limpios y calzados a una escuela pública. La patria es esa comunidad que asegura que a los enfermos se les atiende en los mejores hospitales con los mejores medicamentos. (Transcripción realizada por Toño Fraguas del discurso pronunciado por Pablo Iglesias el día 31 de enero de 2015en la Puerta del Sol de Madrid:http://lafragua.blogspot.com. es/2015/02/discursodepabloiglesiasenlapuerta.html [consulta: 4 febrero 2015]) 
La patria es que nuestros ciudadanos estén bien, en paz, conviviendo en paz, con servicios públicos y que vivamos felices y con cohesión social. (Entrevista 11)

Entonces, yo todo esto del nacionalismo, la patria y tal, y todo eso, bueno, lo pongo siempre en suspensión $[s i c]$. O sea, a mí la patria o la nación es aquella que me permite vivir, [...] que me garantiza derechos, que me garantiza libertades. Esa es mi nación y esa es mi patria. (Entrevista 15)

A mí me gusta que España, todos los españoles, tengamos los mismos derechos en todos los rincones de España, que haya una misma sanidad en toda España, una misma educación, que no haya discriminación porque estás residiendo en una comunidad distinta a otra. (Entrevista 23)

Estos discursos aparecen asociados a comentarios negativos sobre la situación de crisis económica, y con críticas muy fuertes hacia los nacionalismos (tanto el centralista como los periféricos), por anteponer los derechos de los territorios a los de las personas (cuando se expresa la idea vagamente), o, más bien, por anteponer los derechos de las clases capitalistas a los de las clases trabajadoras enmascarándolos en discursos territoriales (cuando se expresa de forma abierta). Este valor es mayoritario en Andalucía y en Cataluña, donde casi el total de entrevistados lo incorpora en su discurso. También es más frecuente entre los entrevistados asimilados a IU que entre los asimilados al PSOE.

En segundo lugar, aparecen valores que sí estamos habituados a encontrar asociados a los discursos de la izquierda, especialmente el denominado diversidad cultural y lingüistica (lo incorpora en su discurso la mitad de los entrevistados). Refleja la importancia que se da al reconocimiento y al respeto por las diferencias culturales, lingüísticas, históricas, etc. entre diferentes territorios y comunidades, caracterizando la diversidad, en sí misma, como un valor que se considera positivamente, como una riqueza. $\mathrm{Su}$ relevancia es similar entre las comunidades autónomas analizadas, excepto en Andalucía, donde algo menos de uno de cada tres entrevistados lo destaca. El multilingüismo, considerado en el análisis como un subcódigo del anterior, es un valor que aparece en ocho de las treinta entrevistas. Recoge la importancia de la riqueza lingüística de España, siendo más frecuente en Cataluña y, especialmente, en Galicia. Por el contrario, aparece en menor medida en Madrid y está ausente entre los entrevistados andaluces.

[En] España solamente podremos salir adelante desde el reconocimiento de la pluralidad, de la diversidad, que eso es lo que nos hace ricos, lo que nos hace fuertes, lo que nos hace encontrar puntos de encuentro que, históricamente, siempre que se ha querido extremar una cosa o la otra, hemos acabado mal. (Entrevista 1)

Bueno, a mí me parece que la solidaridad interterritorial es clara y se debe de respetar, [pero] también se puede respetar lo que somos, que somos diferentes [...], mantener una lengua, mantener determinado patrimonio que necesita 
tener financiación porque somos diferentes y porque eso aporta además a nuestro Estado. Es que España es plural y no podemos renunciar a esos elementos identitarios que nos hacen diferentes del resto del mundo, diferentes de otros países. (Entrevista 14)

Digamos que el concepto de unión como solamente un tipo, un tipo de personas, un tipo de funcionamiento, un tipo de ideología, un tipo de pensamiento, no es correcto. [...] Lo que hay que hacer es respetar [...] a los asturianos como asturianos, con su forma de ser, con su forma de sentir, con sus problemas y con sus ventajas, igual que los andaluces, o los gallegos, o los catalanes. Eso es lo que da riqueza. La uniformidad que sería el considerar todo el territorio lo mismo y tratarles igual, yo creo que nos debilita y nos simplifica, y no es bueno. (Entrevista 23)

El respeto a las diferencias culturales y lingüísticas de los territorios tiene también una vertiente interna en el valor etiquetado como tolerancia, el tercero más destacado (mencionado por dos de cada cinco entrevistados). Este valor implica que los entrevistados valoran positivamente la pluralidad dentro de sus partidos, es decir, dan importancia a saber identificar y reconocerla diferencia, así como la capacidad de convivir con ella, aceptarla y respetarla. Aparece de manera destacada entre los catalanes, seguido de los andaluces y los madrileños, y está ausente entre los gallegos. También es más frecuente entre los entrevistados asimilados al grupo de IU que al grupo del PSOE. La concurrencia que existe entre el valor diversidad cultural y lingüistica y tolerancia en los discursos indica la coherencia en el sistema de valores que comparten y que se aplica tanto hacia fuera (respeto por la diversidad cultural y lingüística en España) como hacia adentro (reconocimiento y respeto por las diferencias y la diversidad dentro del partido). A pesar de la valoración de la diversidad y de la tolerancia como positivos, los entrevistados también reconocen que les genera problemas de imagen cuando son percibidos, desde fuera, como partidos heterogéneos o con falta de consenso.

Por suerte, podemos discutirlo todo. Todo el mundo podemos opinar y, donde hay tantos afiliados, pues hay muchas opiniones. Es lógico, no es una dedocracia como en el PP. Aquí [...] yo creo que más bien por suerte, es una democracia y unos no hablan por no descontentar a otros. Ya está. Simplemente. (Entrevista 27)

Asimismo, cabe destacar el valor de la coexistencia pacifica que aparece en dos de cada cinco entrevistas. Los cuadros medios muestran interés por la idea de la paz y la convivencia, a veces vinculada con el periodo de la democracia o con la Constitución; otras veces, de forma más concreta, se trata de valoraciones positivas sobre la capacidad de los territorios para ponerse de acuerdo y para convivir en paz, o del rechazo de todo lo que suponga polarización o enfrentamiento, también entre comunidades. En este sentido, los entrevistados acentúan el valor del equilibrio (presente en una de cada cuatro 
entrevistas) que refleja la importancia de evitar los extremos. Expresado en positivo, los entrevistados valoran la capacidad para mediar y llegar a consensos; en negativo, se oponen a posicionamientos radicales que dan lugar a enfrentamientos. Muchos de los entrevistados, especialmente en Cataluña, se ven a sí mismos desempeñando este papel de equilibradores entre MadridPP y Cataluña-independentistas. El valor de la democracia (presente en una de cada cinco entrevistas) también refleja la importancia de esta forma de organización política y social, tanto en su vertiente de participación política ciudadana e implicación de la ciudadanía en la política, como en su vertiente instrumental, como el mejor mecanismo (o el único posible) para alcanzar acuerdos y resolver conflictos.

Por lo tanto, eso es una cuestión [...] que tiene que partir del diálogo, de la aceptación y del reconocimiento de todas las partes [...]. Intentar imponer cualquier tipo de criterio aparte de la población [...], en un sentido o en otro, yo creo que no lleva a ningún sitio, solamente a una confrontación. (Entrevista 16)

Igualmente, la descentralización constituye un valor en sí mismo para los entrevistados. Más de un tercio lo incorpora en su discurso sin diferencias notables, ni entre comunidades ni entre partidos. La frecuencia de aparición es ligeramente mayor en Galicia y en los entrevistados asimilados a IU. Más que un medio para conseguir un fin, la descentralización es algo valioso en sí mismo, a lo que los entrevistados asocian características positivas como la cercanía al ciudadano (garantizando mejor servicio público) y la eficacia y la eficiencia en el reparto de recursos públicos.

La descentralización permite más democracia porque permite una participación más directa, más cercana y mayor control por parte de la gente. Eso para mí es la ventaja. [...] Es más lógico pensar que cuanto más se descentraliza más cercana es la participación de la gente, y por eso nosotros decimos que estamos por un Estado federal, porque significa descentralizar, y la descentralización significa mayor democracia, porque es mayor aportación de la gente, mayor cercanía al poder y tal. (Entrevista 15)

El valor de la unidad aparece exclusivamente en los entrevistados madrileños asimilados al PSOE (tres entrevistas), los cuales enfatizan en la idea de que España sea una unidad política o que permanezca unida como país.

En resumen, los valores que aparecen asociados a la idea de España en los discursos de los entrevistados definen el ideal normativo de nación española que tienen los cuadros medios de los partidos de izquierda de ámbito estatal y sus asimilados. Como queda representado en la figura siguiente, primero, y sobre todo, la comunidad política es definida como una comunidad de solidaridad, con un fuerte componente de identidad de clase que encaja con el tipo de nacionalismo de bienestar que podemos encontrar en la literatura y también con la idea de patriotismo social enunciado por dirigentes socialistas como José Luis Rodríguez Zapatero, Pedro Sánchez y diversos líderes de Izquierda Unida, 
Figura 1. Los valores patrióticos de la izquierda (porcentajes de aparición en el discurso de los entrevistados, $N=30$ )

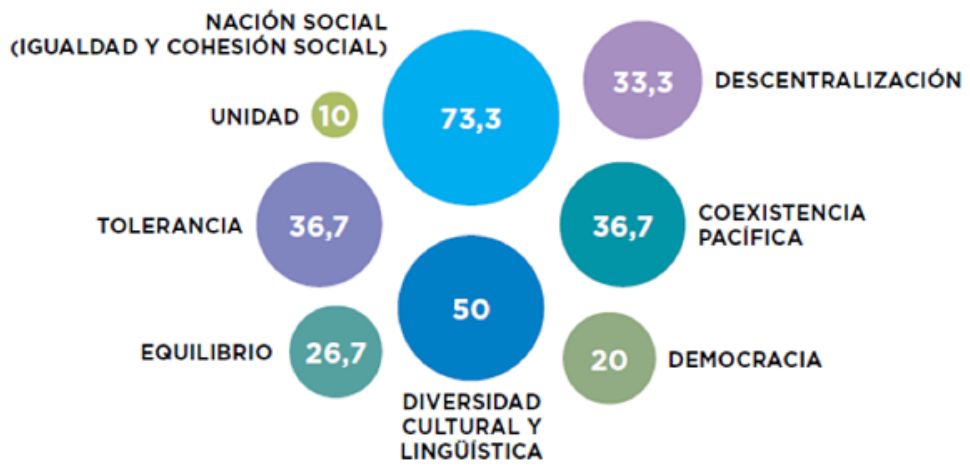

Fuente: elaboración propia.

así como, más recientemente, de Podemos. Esta visión de España, que debe garantizar la igualdad entre ciudadanos y territorios, no implica una visión centralista del Estado, aunque sí el concepto de unidad para algunos (únicamente en Madrid). De hecho, para la mayor parte, la descentralización en sí misma es un valor que va unido a la visión normativa de España. Los valores de la pluriculturalidad (y del multilingüismo), el equilibrio, la coexistencia pacífica y la democracia están también fuertemente unidos a la forma que tienen de entender España los partidos de izquierda de ámbito estatal.

\section{Conclusiones}

Por diferentes cuestiones que abordábamos al principio, frecuentemente se ha afirmado que la izquierda española no se siente vinculada con España, con lo cual se caracteriza por su apatía patriótica. Como hemos constatado, esta afirmación necesita ser matizada. Al considerar un concepto de patriotismo más abierto, basado en la definición de Bar-Tal (1997) y mediante una aproximación inductiva, los resultados obtenidos permiten afirmar que la izquierda de ámbito estatal sí se siente vinculada afectivamente con España. Esta vinculación, que se niega con cierta frecuencia en el discurso explícito de los entrevistados (coincidiendo, en este nivel más superficial, con la literatura previa), está firmemente establecida en el sistema de valores, actitudes y creencias de los cuadros medios en los partidos analizados. Por lo tanto, y en relación con las preguntas y las hipótesis planteadas por este artículo, afirmamos que existe un patriotismo con elementos propios de la izquierda y diferenciado del expresado por otros grupos e ideologías.

Este hallazgo, que coincide también con los valores, los deseos y las aspiraciones de los ciudadanos simpatizantes de izquierda (Ruiz et al., 2015), con- 
trasta, no obstante, con la ausencia (o la debilidad) de discurso afectivo en los programas electorales, centrados de forma casi exclusiva en discutir únicamente la dimensión político-administrativa de la nación, es decir, fundamentalmente, la forma de organización territorial del Estado (Ferri y Ruiz, 2015).

Frente a otras aproximaciones más usuales, la aplicación del concepto de patriotismo de Bar-Tal (1997) nos ha permitido trabajar inductivamente con los discursos de los entrevistados para analizar si existen actitudes de pertenencia a España y la forma en que estas se expresan. La opción de analizar deductivamente, buscando elementos o marcadores de identidad nacional o de patriotismo definidos a priori, hubiera producido resultados pobres, ya que este sentimiento entre la izquierda se caracteriza por elementos que, hasta ahora, han sido ignorados en la investigación sobre nacionalismo español. Como apunta el título del artículo, nuestro hallazgo fundamental es que la izquierda de ámbito estatal en España se caracteriza por su patriotismo social (concepto que ya habían utilizado Field, en 1992, y Lim, en 1995). Es decir, existe una actitud de pertenencia a España que se expresa a través de creencias que connotan afecto, lealtad y preocupación fundamentalmente por el grupo, los españoles (entendidos con una fuerte connotación de clase, como las clases trabajadoras), antes que por el territorio. Además, hablamos de un tipo de patriotismo que, hasta cierto punto, parece emerger en el contexto de la actual crisis económica. No solo en España, sino también en otros países y entre otros líderes políticos, como en el anterior presidente de los Estados Unidos de América (Jackson, 2012: 164) ${ }^{21}$. Esta sospecha ha sido, de hecho, comprobada posteriormente por los autores del artículo mediante un análisis cuantitativo con datos comparativos a nivel internacional (Ruiz et al., 2017; Ruiz et al., 2016). Coincidiendo con los resultados de nuestras entrevistas en España, tanto la experiencia de la monopolización del patriotismo por parte de regímenes fascistas, dictatoriales o totalitarios (Bar-Tal, 1997) como la experiencia de la crisis económica, afectan a la vinculación afectiva con la nación (medida a través de la identidad nacional).

Por ello, más que un patriotismo constitucional, que, como apuntábamos, ha sido apropiado por la derecha y usado para rechazar las demandas de autogobierno en nombre de una ciudadanía común (Kymlicka, 1996: 124; véase también Bastida, 2002; Breda, 2004; Schwartz, 2011), lo que parece emerger entre la izquierda es una idea de "nación de clase» (Lepsius, 2004) que está muy conectada con la de «nacionalismo del bienestar» (McEwen, 2002; McEwen y Moreno, 2005). Es decir, se trata de un tipo de nacionalismo basado en el reconocimiento de derechos de ciudadanía para cubrir las necesidades sociales y económicas de la gente y que también desarrolla sentimientos de pertenencia comunitaria. De este modo, la implantación de un estado de bienestar conlleva también el propósito de construir comunidad nacional, lo que puede ser

21. No obstante, mientras que en EEUU Obama canalizó este estado de opinión pública a través del sistema de partidos tradicional, en Europa han sido los partidos nichos (Meguid,2005) o challenger parties (Hobolt y Tilley, 2016) quienes lo han conseguido. 
especialmente relevante en estados multinacionales. Este tipo de nacionalismo encaja bastante bien en los principios filosóficos y éticos de la izquierda: se inspira en los valores de justicia social e igualdad (Béland y Lecours, 2006: 79), tiene un impacto más directo en mejorar la condiciones de vida de las clases trabajadoras (Bennie et al., 1997) y es una clase de nacionalismo banal (Billig, 1995) que no implica, de forma general, discursos grandilocuentes ni movilización de masas.

Aunque, debido al momento en que se diseña la investigación (2008) y se recogen los datos (2012), nuestra muestra excluye a Podemos, es interesante señalar los paralelismos existentes con los discursos analizados, lo que haría extensible, provisionalmente, nuestras conclusiones también a este partido hasta que se lleven a cabo nuevas investigaciones ${ }^{22}$.

El hallazgo acerca de la importancia de este patriotismo social entre cuadros medios de partidos de izquierda de ámbito estatal en España pone también un signo de interrogación sobre la interpretación que se ha dado a la renuncia de PSOE e IU a esta retórica de lucha de clase en el contexto de la Transición española. En primer lugar, sobre el alcance real de esta renuncia. Como parece seguir muy presente en determinados sectores de ambos partidos y también entre sus simpatizantes (Ruiz et al., 2015), cabe preguntarse si se trata de un efecto contextual provocado por la crisis o si, en realidad, la renuncia nunca caló más allá de la élite del partido. En segundo lugar, sobre su necesidad, modernidad u oportunidad, ya que durante un periodo parece haber forzado a los partidos de izquierda a posicionarse en una dimensión nacionalista, definida desde la derecha española y los nacionalismos periféricos simultáneamente, en la que, como hemos visto, las ideologías de izquierda nunca se han sentido cómodas, y en la que resulta perdedora (Amat, 2012) ${ }^{23}$. Esta incomodidad, notable en los discursos de nuestros entrevistados, provoca la negación en el discurso explícito del vínculo afectivo con España, genera contradicciones y, en general, hace que se trate de quitar importancia a un tema que no se considera propio de la izquierda (Petrocik, 1996; Petrocik et al., 2003: 599; véase

22. Además del ejemplo señalado en la nota 18, existen otros que reflejan diferentes ideas entre las conclusiones que presentamos: «Pablo Iglesias y patriotismo social: Pablo Iglesias agita en el "cinturón rojo" la bandera del patriotismo social ante el 27-S» (http://www.elperiodico.com/ es/noticias/politica/iglesias-agita-cinturon-rojo-bandera-patriotismo-social-4533452); «Pablo Iglesias define Unidos Podemos: "Socialdemócrata, patriótico y plurinacional”» (http://www. elmundo.es/espana/2016/06/06/57553f62268e3e093d8b465e.html); «¿Qué es ser patriota para Podemos?: La formación de Pablo Iglesias busca un discurso sobre la patria» (http:// politica.elpais.com/politica/2015/06/24/actualidad/1435174006_888158.html).

23. Este viraje en las dimensiones de la competición electoral hacia el eje nacionalista, que no beneficia a la izquierda, se produce de forma simultánea a su convergencia ideológica con los conservadores hacia políticas económicas neo-liberales y restrictivas (Fernández-Albertos y Manzano, 2012; Hobolt y Tilley, 2016), limitando así su capacidad de movilizar al electorado sobre el clivaje de clase. En este contexto no sorprende, pues, el éxito electoral de Podemos, usando curiosamente exactamente la misma retórica de los cuadros medios de izquierdas analizados. La recuperación del clivaje de clase frente al eje nacionalista de competición electoral en España, junto con su lenguaje populista, parecería así ser uno de los fundamentos del éxito electoral de Podemos. 
también Bèlanger y Meguid, 2008; Egan, 2013). Todo ello, en un círculo vicioso difícil de romper, dificulta la construcción de un discurso explícito de la izquierda tradicional sobre España, alternativo a las narrativas nacionalistas de la derecha y a los nacionalismos periféricos.

\section{Referencias bibliográficas}

Álvarez, José (2001). Mater dolorosa: La idea de España en el siglo XIX. Madrid: Taurus. АмAT, Francesc (2012). «Identidad y cambio institucional: Los efectos de la competición política». Documentos de Política Comparada, 5, 1-19.

Anderson, Benedict (1991). Comunidades imaginadas: Reflexiones sobre el origen y la difusión del nacionalismo. México: Fondo de Cultura Económica.

Anguita, Julio y Monedero, Juan Carlos (2013a). Conversaciones entre Julio Anguita y Juan Carlos Monedero. Madrid: Icaria.

- (2013b). Contra la ceguera: Cuarenta años luchando por la utopía. Madrid: La Esfera de los Libros.

Balfour, Sebastian y Quiroga, Alejandro (2007). España reinventada: Nación e identidad desde la transición. Barcelona: Península.

Ballester, Mateo (2011). «Auge y declive del Patriotismo Constitucional en España. X Congreso de la Asociación Española de Ciencia Politica [en línea]. <http:// www.aecpa.es/uploads/files/modules/congress/10/papers/203.pdf> [Consulta: 13 febrero 2015].

Banducci, Susan; Karp, Jeffrey A. y Lauf, Edmund (2004). Framing European institutions: Elite leadership, media coverage and support for European integration. Amsterdam: Universidad de Amsterdam. Amsterdam School of Communication Research, ASCoR.

Bar-TaL, Daniel (1997). «Monopolization of Patriotism». En: Bar-Tal, Daniel y Staub, Ervin (eds.). Patriotism in the lives of individuals and groups. Chicago: Nelson-Hall Publishers.

BASTIDA, Xacobe (1998). La nación española y el nacionalismo constitucional. Barcelona: Ariel.

- (2002). «Otra vuelta de tuerca: El patriotismo constitucional español y sus miserias». Cuadernos de Filosofía del Derecho [en línea], 25, 213-246. $<$ http://dx.doi.org/10.14198/doxa2002.25.06>.

- (2007). «La senda constitucional: La nación española y la constitución». En: TAibo, Carlos (eds.). Nacionalismo español: Esencias, memorias e instituciones. Madrid: Libros de la Catarata.

BÉLAND, Daniel y Lecours, André (2006). «Sub-state nationalism and the welfare state: Québec and Canadian federalism». Nations and Nationalism[en línea], 12 (1), 77-96. <http://dx.doi.org/10.1111/j.1469-8129.2006.00231.x>.

BèLAnger, Éric y MEguid, Bonnie M. (2008). «Issue salience, issue ownership, and issue-based vote choice». Electoral Studies, 27, 477-491. $<$ https://doi.org/10.1016/j.electstud.2008.01.001>

Bennie, Lynn; Brand, Jack y Mitcheld, James (1997). How Scotland Votes. Manchester: Manchester University Press.

BiLlig, Michael (1995). Banal Nationalism. Londres: Sage.

BLAs, Andrés de (1991). Tradición republicana y nacionalismo español. Madrid: Tecnos. 
- (2003). «Veinticinco años de Constitución y Nacionalismo». Revista de Derecho Político [en línea], 58-59, 765-775. <http://dx.doi.org/10.5944/rdp.58-59.2003.8920>.

Breda, Vito (2004). "The incoherence of the patriotic state: a critique of 'constitutional patriotism'». Res Publica, 10, 247-265. <http://dx.doi.org/10.1007/s11158-004-0828-x>

Coffey, Amanda y Atkinson, Paul (2003). Encontrar el sentido a los datos cualitativos. Colombia: Universidad Nacional de Antioquia.

Coller, Xaxier y Carrillo, Ana (2014). «Investigar la identidad colectiva». En: Coller, Xaxier (ed.). Perspectivas sobre la identidad andaluza: Políticos, intelectuales y ciudadanía. Sevilla: Fundación Pública Andaluza. Centro de Estudios Andaluces.

Coller, Xaxier y Santana, Andrés (2009). «La homogeneidad social de la elite política: Los parlamentarios de los PANE (1980-2005)». Papers [en línea], 92, 29-50. $<$ http://dx.doi.org/10.5565/rev/papers/v92n0.706>.

Connor, Walker (1994). Ethno-Nationalism: The Quest for Understanding. Princeton: Princeton University Press.

Dalton, Russell J. (1998). «Political support in advanced industrial democracies». Research Monograph Series [en línea], 16, 1-21. <http://dx.doi.org/10.1093/01 98295685.003.0003>.

- (2004). Democratic challenges, democratic choices: The erosion of political support in advanced industrial democracies. Oxford: Oxford University Press.

Dinas, Elias (2012). «Left and right in the Basque country and Catalonia: The meaning of ideology in a nationalist context». South European Society and Politics [en línea], 17 (3), 467-485. <http://dx.doi.org/10.1080/13608746.2012.701898>.

Easton, David (1965). A system analysis of political life. Nueva York: Wiley.

EGAN, Patrick J. (2013). Partisan Priorities: How Issue Ownership Drives and Distorts American Politics. Cambridge: Cambridge University Press.

Entman, Robert M. (2007). "Framing bias: Media in the distribution of power». Journal of Communication [en línea], 57 (1), 163-173. <http://dx.doi.org/10.1111/j.1460-2466.2006.00336.x>.

ERK, Jan (2010). «Is nationalism left or right?: Critical junctures in Québécois nationalism?». Nations and Nationalism [en línea], 16 (3), 423-441. <http://dx.doi.org/10.1111/j.1469-8129.2010.00410.x>.

FARNETI, Roberto (2012). "Cleavage lines in global politics: Left and right, East and West, earth and heaven». Journal of Political Ideologies [en línea], 17 (2), 127-145. <http://dx.doi.org/10.1080/13569317.2012.676850>.

Fernández-Albertos, José y Manzano, Dulce (2012). «The lack of partisan conflic over the welfare state in Spain». South European Society \& Politics, 17 (3), 427-447. <http://dx.doi.org/10.1080/13608746.2012.701895>

Ferri, Elena y Ruiz, Antonia María (2015). «Entre patria y Estado: Formas de nombrar España. Un recorrido por los discursos programáticos de PSOE y AP-PP entre 1977 y 2011». Revista Empiria de Metodología de Ciencias Sociales[en línea], 32, 63-84. <http://dx.doi.org/10.5944/empiria.32.2015.15309>.

FIELD, Geoffrey (1992). «Social patriotism and the British working class: Appearance and disappearance of a tradition». International Labor and Working-Class History [en línea], 42, 20-39.

<http://dx.doi.org/10.1017/s0147547900011212>. 
Fox, Inman (1997). La invención de España: Nacionalismo liberal e identidad nacional. Madrid: Cátedra.

FrIeSE, Susanne (2012). Qualitative data analysis with ATLAS.ti. Londres: Sage.

Fundación Alternativas (2013). 1er Informe sobre la desigualdad en España. Madrid: Fundación Alternativas.

Fundación Foessa (2013). Desigualdad y derechos sociales. Madrid: Fundación Foessa.

Gallego, Raquel; Gomà, Ricard y Subirats, Joan (2005). «Spain, from state welfare to regional welfare?». En: McEwen, Nicola y Moreno, Luis (eds.). The territorial politics of welfare. Londres: Routledge.

García, Antonio (1985). «Evolución ideológica del socialismo en la España actual». Sistema, 68-69, 61-78.

Garzón, Alberto (2013). La gran estafa. Madrid: Destino.

- (2014). La tercera república: Construyamos ya la sociedad de futuro que necesita España. Madrid: Península.

Gellner, Ernest (1998). Nacionalismo. Barcelona: Destino.

- (2008). Naciones y nacionalismo. Madrid: Alianza.

Gillespie, Richard (1989). The Spanish Socialist Party: A History of Factionalism. Oxford: Clarendon Press.

Goodhard, David (2006). Progressive nationalism: Citizenship and the left. Londres: Demos.

Grad, Hector y Martín, Luisa (2003). "Civic" and "ethnic” nationalist discourses in Spanish parliamentary debates». Journal of Language and Politics[en línea], 2 (1), 31-70. <http://dx.doi.org/10.1075/jlp.2.1.04gra>.

Guerra, Alfonso (2013). Una página difícil de arrancar: Memorias de un socialista sin fisuras. Barcelona: Planeta.

Habermas, Jürgen (1992). La necesidad de revisión de la izquierda. Madrid: Tecnos.

Herderson, Ailsa y McEwen, Nicola (2005). "Do shared values underpin national identity?: Examining the role of values in national identity in Canada and the United Kingdom». National Identities [en línea], 7 (12), 173-191. <http://dx.doi.org/10.1080/14608940500144286>.

Новоцт, Sara B. y Tilley, James (2016). "Fleeing the centre: the rise of challenger parties in the aftermath of the euro crisis». West European Politics, 39 (5), 971-991.

Новsвашм, Eric (1996). «Identity politics and the left». New Left Review, I (217), 38-47.

Howell, David (1986). A lost left: Three studies in socialism and nationalism. Chicago: The University of Chicago Press.

Jackson, Ben (2012). "The masses against the classes: One Nation Labour and the revival of social patriotism». Public Policy Research [en línea], 19 (3), 160-165. <http://dx.doi.org/10.1111/j.1744-540x.2012.00702.x>.

Jiménez, Manuel y NAvarro, Luis (2015). «Las huellas electorales del nacionalismo español: Identificación territorial y voto en los partidos políticos de ámbito estatal, 1980-2013». Revista Internacional de Sociología [en línea], 73, 1-20. <http://dx.doi.org/10.3989/ris.2012.02.12>.

Juliá, Santos (1997). Los socialistas en la política española. Madrid: Taurus.

KaIna, Viktoria y Karolewski, Ireneusz P. (2009). «EU governance and European identity». Living Reviews in European Governance [en línea], 4 (2), 1-41. <http://dx.doi.org/10.12942/lreg-2009-2>. 
KasprzaK, Michal (2012). «To reject or not to reject nationalism: Debating Marx and Engels' struggles with nationalism, 1840s-1880s». Nationalities Papers: The Journal of Nationalism and Ethnicity [en línea], 40 (4), 585-606. <http://dx.doi.org/10.1080/00905992.2012.685058>.

Kymlicka, Will (1996). "Social Unity in liberal state». Social Philosophy and Policy [en línea], 13 (1), 105-136. <http://dx.doi.org/10.1017/s0265052500001540>.

Laborda, Juan J. (2002). «Patriotas y de izquierdas». Claves de Razón Práctica [en línea], 122, 47-53.

LAXER, Gordon (2001). «The movement that dare not speak its name: The return of left nationalism/internationalism». Alternatives [en línea], 26, 1-32. <http://dx.doi.org/10.1177/030437540102600101>.

Lepsius, M. Rainer y Campbell, Jean A. (2004). «The Nation and Nationalism in Germany». Social Research, 71 (3), 481-500.

Lim, Jie-Hyun (1995). «Rosa Luxemburg on the dialectics of proletarian internationalism and social patriotism». Science \& Society, 4, 498-530.

Linz, Juan J. (1973). «Early state building and late peripheral nationalisms against the State: The case of Spain». En: Eisenstadt, Shmuel N. y Rokkan, Stein (eds.). Building states and nation: Analysis by region. Londres: Sage.

— (1993). «State Building and Nation Building». European Review, 1 (4), 355-369.

Máiz, Ramón (2003). «Framing the nation: Three rival versions of contemporary nationalist ideology». Journal of Political Ideologies [en línea], 8 (3), 251-267. <http://dx.doi.org/10.1080/1356931032000131165>.

Maravall, José M. (2003). El control de los politicos. Barcelona: Taurus.

- (2008). La confrontación politica. Barcelona: Taurus.

Mar-Molinero, Clare y Smith, Ángel (1996). Nationalism and the nation in the Iberian Peninsula: Competing and conflicting identities. Oxford: Berg.

Márquez, Víctor (1983). Felipe González: Un estilo ético. Barcelona: Círculo de Lectores.

Martín, José L. (1989). Historia del socialismo español, 1939-1977. Barcelona: Conjunto Editorial.

Martínez-Herrera, Enric (2002). «From nation-building to building identification with political communities: Consequences of political decentralization in Spain, the Basque Country, Catalonia and Galicia, 1978-2001». European Journal of Political Research [en línea], 41, 421-53. <http://dx.doi.org/10.1111/1475-6765.00018>.

- (2005). The effects of political decentralization on support for political communities: A multivariate longitudinal and cross-sectional comparison of the Basque Country, Catalonia, Galicia, Quebec and Scotland. Florencia: European University Institute. $\mathrm{PhD}$ tesis.

Mateo, Montse (2005). «La idea de España a finales del s.xx: El nacionalismo español desde la transición». Viento Sur [en línea]. <http://www.vientosur.info/documentos/cuestionnacional-montsemateo.pdf> [Consulta: 23 marzo 2015].

Mateos, Abdón (1993). El PSOE contra Franco. Madrid: Fundación Pablo Iglesias.

McEwen, Nicola (2002). «State welfare nationalism: The territorial impact of welfare state development in Scotland». Regional \& Federal Studies [en línea], 12 (1), $66-90$. <http://dx.doi.org/10.1080/714004724>.

McEwen, Nicola y Moreno, Luis (2005). The territorial politics of welfare. Londres: Routledge. 
Meguid, Bonnie M. (2005). "Competition between Unequals : The Role of Mainstream Party Strategy in Niche Party Success». The American Political Science Review, 99 (3), 347-359. <https://doi.org/10.1017/S0003055405051701>

Méndez, Mónica (2000). La estrategia organizativa del Partido Socialista Obrero Espanol, 1975-1996. Madrid: CIS.

Miles, Matthew; Huberman, Michael y Saldaña, Johnny (2014). Qualitative data analysis: A methods sourcebook. Londres: Sage.

Molina, Daniel (2014). «El PSOE y Cataluña: En busca de la vía federal: 1931-1978». Tiempo y Sociedad, 14, 163-225.

Molina, Fernando (2009). "Realidad y mito del nacionalismo español: Bibliografía reciente y estado de la cuestión». Historia y Política, 21, 275-289.

Müller, Jan-Werner (2007). Constitutional Patriotism. New Jersey: Princeton University Press.

Muñoz, Jordi (2012). La construcción política de la identidad española: ¿Del nacionalcatolicismo al patriotismo democrático? Madrid: CIS.

Nacionalismo español: Discursos y praxis desde la izquierda, 1982-2008. Proyecto financiado por el Ministerio de Ciencia e Innovación. Ref. CSO2008-1182 CPOL.

Navarro, Luis; Ruiz, Antonia M. y Ferri, Elena (2017). «La organización territorial española en crisis: Análisis del pensamiento político de las élites locales y regionales en los partidos de ámbito estatal de izquierda». Revista Española de Sociología [en línea], 26 (1), 21-36. <http://dx.doi:10.22325/fes/res.2016.3>.

Núñez-Seixas, Xosé M. (2010). "La nación en la España del siglo xxi: Un debate inacabable». Pasado y Memoria [en línea], 9, 129-48. <http://dx.doi.org/10.14198/pasado2010.9.06>.

Østerud, Øyvind (1999). Globaliseringen Og Nasjonalstaten. Oslo: Ad Notam Gyldendal.

Pérez, Manuel y Navarro, Luis (2013). «El tercer sector de acción social en España: Situación y retos en un contexto de crisis». Revista Española del Tercer Sector, 23, 41-58.

Petrocik, John R. (1996). «Issue ownership in presidential elections, with a 1980 case study». American Journal of Political Science [en línea], 40 (3), 825-850. <http://dx.doi.org/10.2307/2111797>.

Petrocik, John R.; Benoit, William L. y Hansen, Glenn J. (2003). «Issue ownership and presidential campaigning, 1952-2000». Political Science Quarterly [en línea], 118 (4), 599-626. <http://dx.doi.org/10.1002/j.1538-165x.2003.tb00407.x>.

Quiroga, Alejandro (2008). «Amistades peligrosas: La izquierda y los nacionalismos catalanes y vascos (1975-2008)». Historia y Política, 20, 97-127.

- (2011). «Salvation by betrayal: The left and the Spanish nation». En: Muro, Diego y Alonso, Gregorio (eds.). The politics and memory of democratic transition. Nueva York: Routledge.

Riker, William H. (1986). The art of political manipulation. Nueva York: Yale University Press.

Ruiz, Antonia M. y GonzÁlez, Carmen (2007). «La identidad nacional y europea de los ciudadanos españoles: Un estudio cualitativo de entrevistas y grupos de discusión». Revista de Estudios Políticos, 136, 143-178. 
Ruiz, Antonia M.; GonzÁlez, Manuel T. y Jiménez, Manuel (2015). «Identifying with the nation: Spain's left-wing citizens in an age of crisis». South European Society and Politics [en línea], 20 (4), 487-508. <http://dx.doi.org/10.1080/13608746.2015.1040147>.

Ruiz, Antonia M.; Echavarren, José M. y Aquino, Nieves (2016). «Gone with the crisis?: A multilevel analysis of economy, welfare and attachment to the nation in Europe». 24 Congreso Mundial de Ciencia Política. Polonia, del 23 al 28 de julio.

Ruiz, Antonia M.; Ferri, Elena y Navarro, Luis (2017). "Country-level variables and imagined national communities within EU-15 countries». Politica y Sociedad [en línea], 54 (1), 277-300. <http://dx.doi.org/10.5209/POSO.50089>.

Ruiz, Jorge (2009). "Análisis sociológico del discurso: Métodos y lógicas». Forum Qualitative Social Research, 10(2), art. 26.

SALDAÑA, Johnny (2013). The coding manual for qualitative researchers. Londres: Sage.

SChwartz, Alex (2011). "Patriotism or integrity? Constitutional community in divided societies». Oxford Journal of Legal Studies, 31 (3), 503-526. <https://doi.org/10.1093/ojls/gqr010>

Schwarzmantel, John (2012). "Rethinking Marxism and Nationalism in an Age of Globalization». Rethinking Marxism: A Journal of Economics, Culture \& Society [en línea], 24 (1), 144-161. <http://dx.doi.org/10.1080/08935696.2012.635049>.

Smiley, David V. (1987). The Federal Condition in Canada. Toronto: McGraw-Hill Ryerson.

Smith, Anthony D. (1991). National identity. Londres: Penguin Books.

- (2007). Nations and nationalism in the global era. Londres: Polity Press.

- (2010). Nationalism. Londres: Polity Press.

TALSHIR, Gayil (2005). «Knowing right from left: The politics of identity between the radical left and far right». Journal of Political Ideologies [en línea], 10 (3), 311-335. <http://dx.doi.org/10.1080/13569310500244339>.

Tezanos, José F. (1983). Sociología del socialismo español. Madrid: Tecnos.

ThORLAKSON, Lori (2001).«Federalism and party organisational adaptation: Across-national comparison». ECPR Joint Sessions of Workshops. Grenoble, del 6 al 11 de abril.

Verge, Tània (2007). Partidos y representación política: Las dimensiones del cambio en los partidos políticos españoles, 1976-2006. Madrid: CIS.

VERge, Tània y BARberÀ, Óscar (2009). «Descentralización y estrategias organizativas: Las relaciones especiales entre partidos de ámbito estatal (PAE) y partidos de ámbito no estatal (PANE) en España». Institut de Ciències Polítiques i Socials, 281, 1-33.

Ward, Paul (1998). Red Flag \& Union Jack: Englishness, patriotism and the British left, 1881-1924. Martlesham: Boydell Press.

YACK, Bernard (2001). «Popular sovereignty and nationalism». Political Theory [en línea], 29 (4), 517-536.

<http://dx.doi.org/10.1177/0090591701029004003>. 


\section{Anexo 1}

Relación de personas entrevistadas de acuerdo con el partido político de izquierda en que milita, la comunidad autónoma a la que pertenece y el tipo de cargo que ejerce*

\begin{tabular}{|c|c|c|c|}
\hline Nombre & Partido & Comunidad autónoma & Cargo \\
\hline Ana Doblas & IU & Andalucía & Regional \\
\hline Inmaculada Nieto & IU & Andalucía & Regional \\
\hline Antonio L. Girón & IU & Andalucía & Local \\
\hline Antonio Benjumea & PSOE & Andalucía & Local \\
\hline Carmelo Gómez & PSOE & Andalucía & Regional \\
\hline Manuel Jiménez & PSOE & Andalucía & Regional \\
\hline Pablo Morterero & PSOE & Andalucía & Local \\
\hline Àlex Mañas & ICV & Cataluña & Local \\
\hline Arnau Funes & ICV & Cataluña & Local \\
\hline Dolors Camats & ICV & Cataluña & Regional \\
\hline Hortènsia Grau & ICV & Cataluña & Regional \\
\hline Alfonso Salmerón & EUiA & Cataluña & Local \\
\hline Joan Josep Nuet & EUiA & Cataluña & Regional \\
\hline Cristóbal González & PSC & Cataluña & Local \\
\hline Ernest Maragall & PSC & Cataluña & Regional \\
\hline Joaquim Nadal & PSC & Cataluña & Regional \\
\hline Abel Losada & PSdeG & Galicia & Regional \\
\hline Beatriz Sestayo & PSdeG & Galicia & Regional \\
\hline Mar Barcón & PSdeG & Galicia & Local \\
\hline Ceferino Díaz & PSdeG & Galicia & Regional \\
\hline Francisco Cerviño & PSdeG & Galicia & Regional \\
\hline Ángel Pérez & IU & Madrid & Local \\
\hline Gregorio Gordo & IU & Madrid & Regional \\
\hline Jordi Escuer & IU & Madrid & Local \\
\hline Libertad Martínez & IU & Madrid & Regional \\
\hline Gloria Mora & PSOE & Madrid & Local \\
\hline Isabel López del Arco & PSOE & Madrid & Local \\
\hline Jesús Barranco & PSOE & Madrid & Local \\
\hline Joaquín Leguina & PSOE & Madrid & Local \\
\hline Nicolás Rodríguez & PSOE & Madrid & Local \\
\hline
\end{tabular}

* Datos referidos a 2012, año de realización de las entrevistas. 


\section{Anexo 2}

Porcentajes de aparición de códigos seleccionados en el discurso de los entrevistados según la comunidad autónoma a la que pertenecen y el partido político de izquierda en que militan

\begin{tabular}{|c|c|c|c|c|c|c|c|}
\hline Códigos & $\begin{array}{c}\text { Porcentaje } \\
\text { total } \\
\text { entrevistas }\end{array}$ & Cataluña & Galicia & Madrid & Andalucía & IU & PSOE \\
\hline Dificultades para definir España & 66,7 & 88,9 & 40,0 & 55,6 & 71,4 & 76,9 & 58,8 \\
\hline $\begin{array}{l}\text { Percepción sobre alienación } \\
\text { de la ciudadanía }\end{array}$ & 40,0 & 0,0 & 40,0 & 77,8 & 42,9 & 46,2 & 35,3 \\
\hline $\begin{array}{l}\text { Referencias a símbolos } \\
\text { españoles }\end{array}$ & 90,0 & 66,7 & 100,0 & 100,0 & 100,0 & 84,6 & 94,1 \\
\hline $\begin{array}{l}\text { España como estructura } \\
\text { político-administrativa }\end{array}$ & 70,0 & - & - & - & - & - & - \\
\hline $\begin{array}{l}\text { España como estructura } \\
\text { político-administrativa: } \\
\text { como Estado }\end{array}$ & 40,0 & 44,4 & 40,0 & 33,3 & 42,9 & 53,8 & 29,4 \\
\hline $\begin{array}{l}\text { España como estructura } \\
\text { político-administrativa: } \\
\text { como país }\end{array}$ & 36,7 & 11,1 & 20,0 & 55,6 & 57,1 & 23,1 & 47,1 \\
\hline $\begin{array}{l}\text { España como estructura } \\
\text { político-administrativa: } \\
\text { como otra forma }\end{array}$ & 26,7 & 22,2 & 40,0 & 33,3 & 14,3 & 15,4 & 35,3 \\
\hline $\begin{array}{l}\text { España como comunidad } \\
\text { afectiva (con sentimiento } \\
\text { de pertenencia) }\end{array}$ & 93,0 & - & - & - & - & - & - \\
\hline $\begin{array}{l}\text { España como comunidad } \\
\text { política: existencia de una } \\
\text { historia común }\end{array}$ & 53,3 & 33,3 & 80,0 & 44,4 & 71,4 & 46,2 & 58,8 \\
\hline $\begin{array}{l}\text { España como comunidad política: } \\
\text { existencia de otros elementos } \\
\text { comunitarios }\end{array}$ & 76,7 & 66,7 & 80,0 & 77,8 & 85,7 & 76,9 & 76,5 \\
\hline Valor: nación social & 73,3 & 77,8 & 60,0 & 66,7 & 85,7 & 92,3 & 58,8 \\
\hline $\begin{array}{l}\text { Valor: diversidad cultural } \\
\text { y lingüística }\end{array}$ & 50,0 & 55,6 & 60,0 & 55,6 & 28,6 & 53,8 & 47,1 \\
\hline Valor: tolerancia & 36,7 & 66,7 & 0,0 & 22,2 & 42,9 & 46,2 & 29,4 \\
\hline Valor: coexistencia pacífica & 36,7 & 44,4 & 20,0 & 44,4 & 28,6 & 38,5 & 35,3 \\
\hline Valor: descentralización & 33,3 & 33,3 & 40,0 & 33,3 & 28,6 & 38,5 & 29,4 \\
\hline Valor: equilibrio & 26,7 & 33,3 & 20,0 & 22,2 & 28,6 & 38,5 & 17,6 \\
\hline Valor: democracia & 20,0 & 22,2 & 20,0 & 22,2 & 14,3 & 15,4 & 23,5 \\
\hline Valor: unidad & 10,0 & 0,0 & 0,0 & 33,3 & 0,0 & 0,0 & 17,6 \\
\hline TOTAL (N) & 30 & 9 & 5 & 9 & 7 & 13 & 17 \\
\hline
\end{tabular}

